\title{
Influence of Day-length on Flowering of Ri-transformed Cichorium intybus L. Plants
}

\author{
Masahiko Inoguchi*, Hideyo NishimurA*, Shingo OKADA* and Jiro Kato*
}

\section{Introduction}

The soil bacterium Agrobacterium rhizogenes induces the development of hairy roots on many dicotyledonous plant species. The infectious bacterium introduces the T-DNA region of its Ri plasmid into the host plant cell to stably transform it (see review ${ }^{1)}$ ). Plants can usually be regenerated from hairy roots with the ordinary culture conditions for the given plant species. Many transgenic plants with the T-DNA(s) from Ri plasmids have been established in various species so far ${ }^{1}$. Such transgenic plants were observed to exhibit certain characteristics different from untransformed plants. Some of the commonly observed characteristics among the Ri-transformants are: rapidly growing and branching roots, wrinkled leaves, dwarfism, and reduced apical dominance $^{2)}$. Flowering response has also been shown to be modified in the Ri-transformants. For example, Oono et al. reported that Ri-transformants of a day-neutral tobacco showed early flowering when compared to the untransformed plants ${ }^{3)}$. Thus the Ri-transformant can be a good material to study mechanisms regulating flowering. Any deviation or modification of flowering behavior could be attributed to the introduced T-DNA.

Witloof chicory (Cichorium intybus L. var. Witloof) is a biennial plant that requires vernalization and subsequent exposure to long-days for flowering (see review $\left.{ }^{4}\right)$. Recently, Kamada $e t$ al. reported that Ri-transformed chicory plants did not require vernalization for flowering ${ }^{5)}$. In this report, we examined the influence of day-length on flowering of Ri-transformed chicory plants.

\section{Requirements for flowering of normal chicory plants in vitro}

We first studied the requirements for flowering of an untransformed chicory plant grown in vitro. Seeds of Witloof chicory cv. Vilmorin No.5(Vilmorin, France) were surface sterilized by a brief soaking in $70 \%$ ethanol followed by soaking in $1 \%$ sodium hypochlorite solution for $15 \mathrm{~min}$. The

Table 1. Influence of vernalization on bolting of normal chicory seedlings in vitro.

\begin{tabular}{cccc}
\hline Experiment & Light regime & No. tested & No. bolted $^{* 1}$ \\
\hline $\begin{array}{c}\text { without vernalization } \\
1\end{array}$ & continuous $\mathrm{LD}$ & 5 & 1 \\
2 & continuous $\mathrm{SD}$ & 5 & 0 \\
3 & $\mathrm{SD} 4$ weeks $\rightarrow \mathrm{LD}$ & 5 & 1 \\
\hline with vernalization & & & \\
4 & $\mathrm{SD} 2$ weeks $\rightarrow \mathrm{V}^{* 2} \rightarrow \mathrm{LD}$ & 5 & 0 \\
5 & $\mathrm{SD} 4$ weeks $\rightarrow \mathrm{V}^{* 2} \rightarrow \mathrm{LD}$ & 5 & 3 \\
6 & $\mathrm{SD} 6$ weeks $\rightarrow \mathrm{V}^{* 2} \rightarrow \mathrm{LD}$ & 5 & 3 \\
7 & $\mathrm{SD} 8$ weeks $\rightarrow \mathrm{V}^{* 2} \rightarrow \mathrm{LD}$ & 5 & 4 \\
\hline
\end{tabular}

${ }^{* 1}$ scored at month 4 after sowing.

*2 vernalization ( 2 weeks at $4^{\circ} \mathrm{C}$ in darkness).

\footnotetext{
${ }^{*}$ Department of Biochemistry, Faculty of Science, Okayama University of Science, 1-1 Ridai-cho, Okayama 700, Japan
} 
seeds were then cultured on Murashige and Skoog's(MS) medium ${ }^{6)}$ solidified with $0.2 \%$ gellan gum in a $9 \mathrm{~cm}$ petri dish for germination. Two-week-old seedlings were then transferred to a $900 \mathrm{~m} l$ culture bottle containing $200 \mathrm{~m} l$ of MS solid medium. Chicory seedlings germinated in the short -day condition ( $8 \mathrm{~h}$ photoperiods, $20,000 \mathrm{~lx}, 25^{\circ} \mathrm{C}$ ) were exposed to $4^{\circ} \mathrm{C}$ for two weeks in darkness at various times after sowing, then transferred into the long-day condition ( $16 \mathrm{~h}$ photoperiods, 20, 000 $1 \mathrm{x}, 25^{\circ} \mathrm{C}$ ). Bolting was observed four months after sowing from seedlings vernalized when they were at least two weeks old (experiments 4 to 7 in Table 1). These stalks flowered after subculturing them to a new culture bottle. Although the number of seedlings used and replication were insufficient and bolting was observed from few seedlings that were not vernalized (experiments 1 to 3 in Table 1), these results suggest that chicory requires vernalization for flowering even in vitro. However, occasional bolting was observed more frequently from unvernalized plants when the culture period was prolonged beyond four months (data not shown).

\section{Flowering of $\mathbf{L D}$-transformant}

To determine the effect of the long-day condition on flowering of Ri-transformed chicory, we established Ri-transformants either under long-day or short-day conditions.

Hairy roots were induced with $A$. rhizogenes strain $\mathrm{A} 4^{7)}$ by conventional leaf disk method ${ }^{8)}$. Plants were regenarated from hairy roots by culturing them on MS solid medium containing 0.01 $\mathrm{mg} / l \mathrm{NAA}$ and $2 \mathrm{mg} / l \mathrm{BA}$. The regenerants were maintained in $900 \mathrm{~m} l$ culture bottles containing $200 \mathrm{~m} l$ of MS solid medium. Whenever a transformant was established under long-day condition

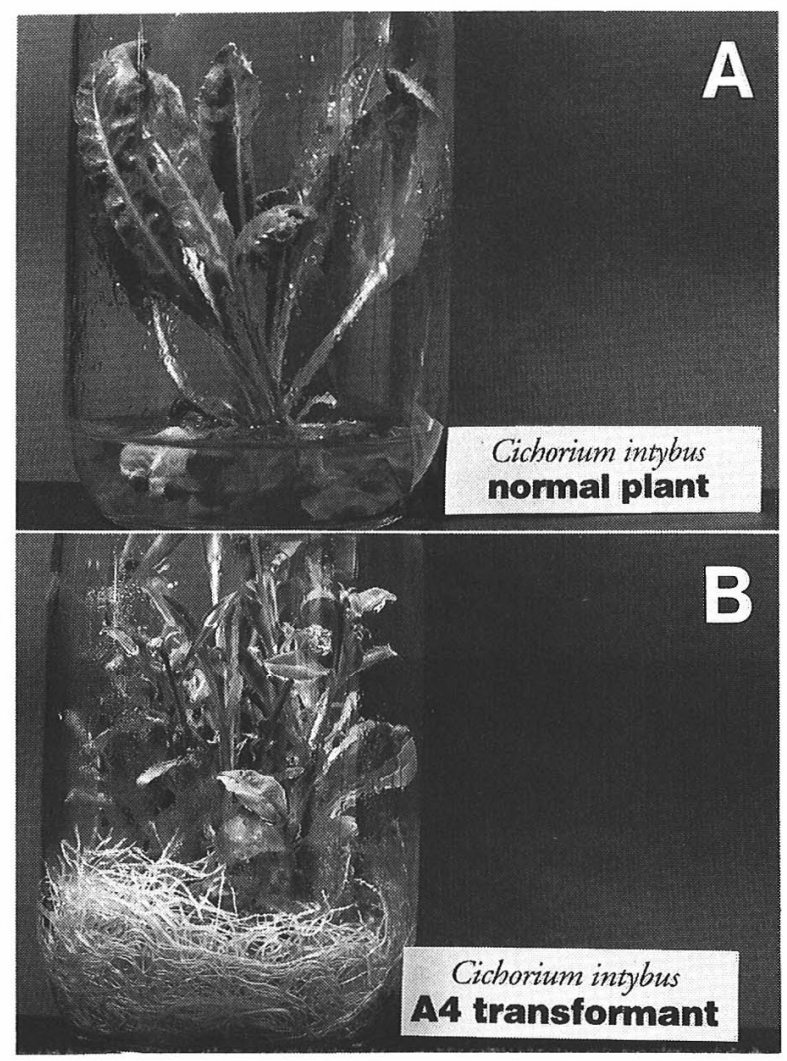

Fig. 1 Flowering of LD-transformed chicory without vernalization under long-day condition. A: An untransformed chicory plant grown under long-day condition without vernalization. B: A LD-transformed chicory plant grown under the same condition as A. Note flower stalks with bracts and well-developed roots on the LD-transformed plant. 
Table 2. Influence of day-length during plant regeneration from leaves of flowering chicory on bolting of regenerants.

\begin{tabular}{cccc}
\hline Mother plant & Light regime & No. tested & No. bolted $^{* 1}$ \\
\hline LD $-18^{* 2}$ & LD & 17 & 11 \\
LD $18^{* 2}$ & SD & 14 & 4 \\
\hline Normal $^{* 3}$ & LD & 12 & 0 \\
Normal $^{* 3}$ & SD & 12 & 0 \\
\hline
\end{tabular}

${ }^{* 1}$ scored at week 8 after the induction of regeneration.

${ }^{* 2}$ LD-transformant \# 18.

${ }^{* 3}$ flowering untransformed plant.

(LD-transformant), the flowering process was initiated when the plantlet was regenerated from a hairy root (Fig. 1), confirming the report of Kamada et al. ${ }^{5}$.

We further examined the effect of day-length on flowering of regenerants from leaves of the LD -transformant. To induce adventitious buds, leaf disks ( $c a .1 \mathrm{~cm}$ square) were cultured on MS solid medium containing $0.01 \mathrm{mg} / l \mathrm{NAA}$ and $2 \mathrm{mg} / l \mathrm{BA}$. Regenerants from a flowering LD-transformant(LD-18) were induced and grown either under long-day or short-day conditions without vernalization, and bolting of the regenerants was scored at week 8 after the induction of regeneration. There were more plants bolted to flower under the long-day condition than under the short -day condition (Table 2). When regenerants were induced from leaves of a flowering, untransformed plant, however, no bolting was observed under either light regime(Table 2). On the other hand, Harada reported that plants regenerated from flower stalks of untransformed chicory flowered under long-day condition without vernalization ${ }^{9}$. These imply that the flowering stimulus in the untransformed plant did not remain in the leaves but remain in the flower stalks, whereas the stimulus in the LD-transformant remained or was produced even in leaf segments.

\section{Flowering of $S D$-transformant}

We then established a Ri-transformed chicory plant that had never experienced a long-day condition nor vernalization. To achieve this, we cultivated a mother plant and induced a hairy root on it; a Ri-transformed plant was then regenerated from the hairy root as described in the last section. All these were done under short-day condition at $25^{\circ} \mathrm{C}$. For unknown reasons, however, only one hairy root line could be isolated under the short-day condition after repeated infection experiments.

The short-day transformant (SD-transformant, SD-1) did not flower for at least four months after regeneration (Fig. 2) and this duration was sufficient for the LD-transformants to form flowers. When the SD-transformant was placed under the long-day condition, bolting occurred within 7 weeks (Fig. 2) and flowers were observed. The plant continued to flower even when it was transferred back to the short-day condition(data not shown).

\section{PCR and Southern analyses}

Finally, genomic DNA extracted from the LD-transformants, the SD-transformant and an untransformed plant were analyzed by PCR amplification for the TL- and the TR-DNA sequences. Genomic DNA was extracted from $10 \mathrm{~g}$ fresh weight of leaf tissue of a transformed or a control plant according to the method of Paszkowski et al. ${ }^{10}$. One hundred ng of the DNA were used as the template for a PCR reaction. Primers (rolBAS and rolCAS) for the amplification of an internal part of the TL-DNA of pRiA4b were prepared according to Handa ${ }^{11)}$. For the amplification of the TR-DNA, primers (Com-ags and Com-mas 1') with sequences 5'-CTCTGGGCCTGCAAGGATGC$3^{\prime}$ and $5^{\prime}$-ACGAACATCGGTCTCAATG-3', respectively, were designed and synthesized in this 


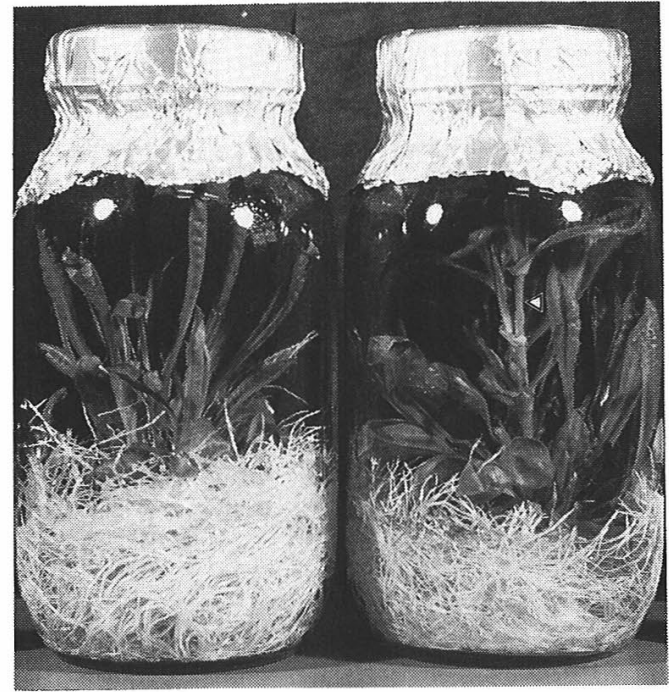

Fig. 2 Effect of day length on flowering of SD-transformed chicory plants.

Two shoots separated from a SD-transformant and cultured under short-day (left) or long-day (right) conditions for 24 days. Note the flower stalk (indicated by open arrowhead) on the LD-grown plant.

(A)

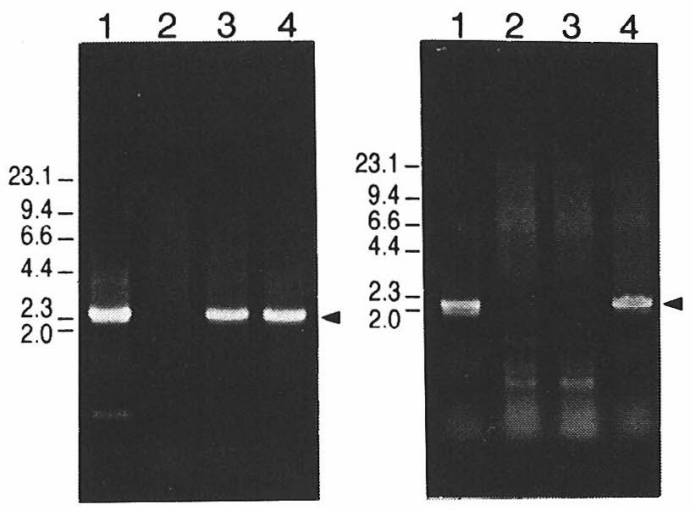

(B)

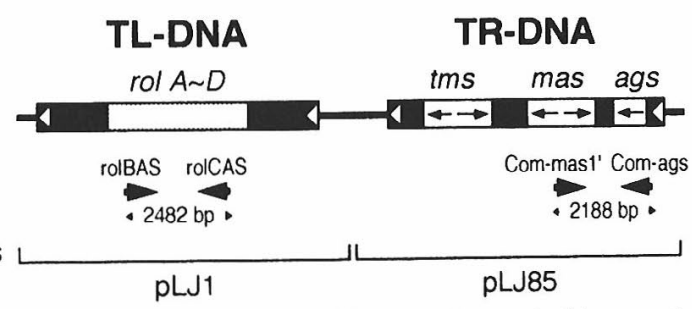

Fig. 3 PCR amplification of T-DNA sequences in Ri-transformed chicory plants.

A: Ethidium bromide-stained gels for the TL-(left panel) and the TR-(right panel) DNA fragments. For both panels, lane 1, cosmid clones containing the TL-and the TR -DNA, respectively; lane 2, control (untransformed) plant; lane 3, SD-transformant SD -1; lane 4, LD-transformant LD-18. B: Schematic diagram for the amplification of a $2382 \mathrm{bp}$ TL- and a $2188 \mathrm{bp}$ TR-DNA sequences. Shaded area indicates the core T-DNA region containing rolA $\sim D$ loci. tms, mas and ags are genetic loci coding for auxin, mannopine and agropine synthase, respectively. Arrows in the T-DNA diagram indicate genes in each locus. rolBAS and rolCAS, and Com-mas 1' and Com-ags are primer pairs to amplify the TL- and the TR-DNA fragments, respectively. pLJ 1 and pLJ 85 are cosmid clones containing entire TL-DNA and TR-DNA, respectively, of pRiHRI ${ }^{12)}$. 
work. The PCR reaction was carried out with the following program; preheating at $94^{\circ} \mathrm{C}$ for 10 min., 30 cycles of $94^{\circ} \mathrm{C}$ for $1 \mathrm{~min}$., $55^{\circ} \mathrm{C}$ for $1 \mathrm{~min}$. and $72^{\circ} \mathrm{C}$ for $2 \mathrm{~min}$., and final elongation at $72^{\circ} \mathrm{C}$ for $7 \mathrm{~min}$. A portion of the amplified DNA was separated by the agarose gel electrophoresis and stained with ethidium bromide to be photographed.

Both the TL- and the TR-DNA sequences were detected in all LD-transformants tested, whereas only the TL-DNA sequence was detected in the SD-transformant SD-1(Fig. 3). Those amplified sequences were further confirmed to be the T-DNA sequences by Southern hybridization(data not shown).

As the SD-transformant carried the Ri TL-DNA was able to flower under the long-day condition without vernalization, it implies that gene(s) on the TL-DNA was (were) responsible for the altered flowering response of the Ri-transformants. Earlier report by Kamada et $a l .{ }^{5}$ ) revealed that a transformed chicory with only the rolC gene could flower without vernalization.

\section{Conclusion}

In this study, we first demonstrated that Ri-transformed chicory established under long-day condition could undergo the complete flowering process with no need of vernalization, which was required by untransformed seedlings in vitro as known for field-grown plants. The result is consistent with that reported by Kamada et al. ${ }^{5}$. Furthermore, our results demonstrated that flowering of Ri-transformed chicory was, to certain degree, influenced by the long-day condition based on the following observations: 1) transformant established completely under the short-day condition did not flower; and 2) short-day reduced the flowering response of shoots regenerated from LD-transformant when compared to that of the long-day.

\section{Acknowledgment}

The authors would like to thank Dr. C. S. Loh for his critical reading of the manuscript.

(Accepted December 28, 1994)

\section{References}

1) Birot, A. -M., D. Bouchez, F. Casse-Delbart, M. Durand-Tardif, L. Jouanin, V. Pautot, C. Robaglia, D. Tepfer, M. Tepfer, J. Tourneur, F. Vilaine, 1987. Plant Physiol. Biochem., 25: 323-335.

2) Tepfer, D., 1984. Cell, 37: 959-967.

3) Oono, Y., K. Kanaya, H. Uchimiya, 1990. Jap. J. Genet., 65: 7-16.

4) Schoofs, J., E. De Langhe, 1988. In "Biotechnology in Agriculture and Forestry" (ed. by Bajaj, Y. P. S.), Vol. 6 Crops II, p. 294-321, Springer-Verlag, Berlin.

5) Kamada, H., A. Ono, T. Saitou, H. Harada, 1992. Plant Tissue Culture Letters, 9: 206-208.

6) Murashige, T., F. Skoog, 1962. Physiol. Plant., 15: 473-497.

7) Moore, L., G. Warren, G. Strobel, 1979. Plasmid, 2: 617-626.

8) Horsh, R. B., J. E. Fry, N. L. Hoffman, D. Eichholtz, S. G. Rogers, R. T. Fraley, 1985. Science, 227: 12291231.

9) Harada, H., 1966. Bot. Mag. Tokyo, 79: 119-123.

10) Paszkowski, J., R. D. Shillito, M. Saul, V. Mandak, T. Hohn, B. Hohn, I. Potrykus, 1984. EMBO J., 3: 2717 -2722 .

11) Handa, T., 1992. Plant Science, 81: 199-206.

12) Jouanin, L., 1984. Plasmid, 12: 92-102. 